\title{
Congress Announcement
}

\section{International Symposium on Polymer Analysis and Characterization}

The Seventh International Symposium on Polymer Analysis and Characterization (ISPAC-7) will be held May 23-25, 1994 in Les Diabierets, Switzerland. This three-day Symposium will consist of poster sessions, invited lectures, and round-table discussions and information exchange on recent advances in polymer characterization approaches, techniques and applications.

ISPAC-7 will focus on molecular characterization in relationship to properties of polymeric systems. Topics will include aqueous polymeric systems (water-soluble polymers, interacting systems, and physical and chemical gels) and heterogeneous polymeric materials (blends, composites, and multilayered materials). In addition, an introductory course on polyelectrolytes and the characterization of water-soluble polymers will be held on Sunday, May 22, preceding the Symposium.

Further information and registration forms may be obtained from ISPAC Registration, 815 Don Gaspar, Sante Fe, NM 87501, Tel. 505/989-4735; Fax 505/ 989-1073, or Dr. M. Rinaudo, CERMAV-CNRS, B.P. 53X, 38041 Grenoble, Cedex, France, Tel.: 33/ 76541145; Fax: 33/76547203.

\section{Erratum}

Baur H: Thermodynamics of relaxation processes in the glass transition region II, Rheol. Acta 31: 545-553 (1992).

The above manuscript of Dr. H. Baur has been published in its original form. The statement at the end of the text "in revised form on July 28, 1992" is incorrect. It should have read "accepted in its original form on July 28 , 1992:"

The Editor 